\title{
Clinical Significance of Serum Galectin-9 and Soluble CD155 Levels in Patients with Systemic Sclerosis
}

\author{
Mami Chihara, Miki Kurita, Yuki Yoshihara, Akihiko Asahina, and Koichi Yanaba \\ Department of Dermatology, The Jikei University School of Medicine, Tokyo, Japan \\ Correspondence should be addressed to Koichi Yanaba; yanaba@jikei.ac.jp
}

Received 8 June 2018; Revised 21 September 2018; Accepted 2 October 2018; Published 27 November 2018

Academic Editor: Theresa Hautz

Copyright ( $) 2018$ Mami Chihara et al. This is an open access article distributed under the Creative Commons Attribution License, which permits unrestricted use, distribution, and reproduction in any medium, provided the original work is properly cited.

\begin{abstract}
Signaling through coinhibitory receptors downregulates the immune response to prevent excessive immune activation and maintain optimal immunity and tolerance. The aim of this study was to examine the levels of the soluble forms of coinhibitory receptors and their ligands, namely, galectin-9 (the ligand of T-cell immunoglobulin and mucin domain 3) and CD155 (the ligand of $\mathrm{T}$ cell immunoglobulin and immunoreceptor tyrosine-based inhibitory motif domain), and their association with clinical features in patients with systemic sclerosis (SSc). The serum levels of galectin-9 and soluble sCD155 were examined by enzyme-linked immunosorbent assays in patients with SSc, and the results were evaluated with respect to clinical features. Patients with SSc exhibited raised serum levels of galectin-9, but not sCD155. Serum galectin-9 levels were raised not only in patients with diffuse cutaneous SSc but also in patients with limited cutaneous SSc. Furthermore, serum galectin-9 levels correlated positively with the erythrocyte sedimentation rate. In addition, increased serum galectin- 9 levels tended to be associated with higher mortality and serious organ involvement. These results suggest that galectin-9, but not CD155, may be involved in the pathogenesis of SSc. In addition, the measurement of serum galectin-9 levels could be used to predict serious organ involvement and high mortality in patients with SSc.
\end{abstract}

\section{Background}

Systemic sclerosis (SSc) is a generalized connective tissue disorder of unknown etiology and is characterized by excessive fibrosis and microvascular damage in the skin and various internal organs. A growing body of evidence has demonstrated that SSc is an autoimmune disorder because of the presence of disease-associated autoantibodies and a number of immunologic abnormalities [1]. In particular, cutaneous mononuclear cells that infiltrate early SSc skin lesions consist of mostly activated $\mathrm{T}$ cells [2]; the degree of cell infiltration correlates with the severity of skin thickening [3]. These infiltrating cells are suggested to release various cytokines, chemokines, or growth factors that play an important role in the initiation and development of fibrosis in SSc [4].

$\mathrm{T}$ cells are initially stimulated by signaling through antigen-specific $\mathrm{T}$ cell receptors, while optimal $\mathrm{T}$ cell activation further requires both stimulatory and inhibitory secondary signals through costimulatory and coinhibitory receptors, respectively $[5,6]$. In particular, signaling through coinhibitory receptors downregulates the immune response to prevent excessive immune activation and maintain optimal immunity and tolerance [7]; therefore, coinhibitory receptors are considered to play a crucial role in autoimmunity [8]. Remarkably, the administration of the fusion protein of cytotoxic $\mathrm{T}$ lymphocyte-associated antigen 4 , which is the most characterized coinhibitory receptor, improves SSc skin fibrosis in mice and humans $[9,10]$. Furthermore, multiple soluble forms of coinhibitory receptors, including cytotoxic $\mathrm{T}$ lymphocyte-associated antigen 4, programmed death-1, and T-cell immunoglobulin and mucin domain 3 (TIM-3), have been demonstrated to play a role in the pathogenesis of SSc [11-13]. Therefore, we hypothesized that other soluble forms of coinhibitory receptors and their ligands, such as galectin-9 (the ligand of TIM-3) and CD155 (the ligand of T cell immunoglobulin and immunoreceptor tyrosine-based inhibitory motif domain), may also play a role in the pathogenesis of SSc. In this study, we examined the levels of serum galectin-9 and soluble sCD155 in 
patients with SSc and evaluated the results with respect to clinical features.

\section{Material and Methods}

2.1. Patients and Controls. For the measurement of serum galectin-9 and sCD155 levels, samples were obtained from 62 Japanese patients with SSc (60 women and 2 men; median age 49 (range, 9-78) years). All patients fulfilled the criteria for SSc $[14,15]$. The patients were classified according to the system proposed by LeRoy et al. [16]: 33 patients had limited cutaneous SSc (lcSSc) and 29 had diffuse cutaneous $\mathrm{SSc}$ (dcSSc). Antitopoisomerase I (topo I) antibodies (Abs) were present in 23 patients, anticentromere Abs were present in 28, anti-U1RNP Abs were present in 2, and anti-RNA polymerase I and III Abs were present in 2. No patients were positive for anti-U3RNP Abs. The remaining 7 patients were negative for all of these Abs. Mean disease duration was $4.6 \pm 5.0$ (range, $0.2-20$ ) years. Duration was calculated from the time of the onset of the first clear clinical manifestation of SSc (excluding Raynaud's phenomenon). None of the patients had received corticosteroids or other immunosuppressants. Twenty-six age- and sex-matched healthy Japanese individuals were included in the study as healthy controls.

2.2. Clinical Assessment. During their first visit, all patients underwent a physical examination, complete medical histories were obtained, and laboratory tests were performed. Organ system involvement was defined as described previously [4, 17-19]; lung: bibasilar fibrosis on chest radiography and high-resolution computed tomography; esophagus: hypomotility shown by barium radiography; heart: pericarditis, congestive heart failure, or arrhythmia requiring treatment; kidney: malignant hypertension and rapidly progressive renal failure with no other explanation; joints: inflammatory polyarthralgia or arthritis; and muscle: proximal muscle weakness and elevated serum creatine kinase level. Interstitial lung disease was defined as bibasilar interstitial fibrosis on chest high-resolution computed tomography. In addition, a pulmonary function test, including vital capacity (VC) and diffusion capacity for carbon monoxide (DLco), was performed to examine the severity of interstitial lung disease. DLco $<75 \%$ and $\mathrm{VC}<80 \%$ of predicted normal values were considered abnormal. The presence of the elevated right ventricular systolic pressure of $\geq 40 \mathrm{~mm} \mathrm{Hg}$ by Doppler echocardiogram was used as a screening threshold for pulmonary arterial hypertension. Pulmonary arterial hypertension was confirmed by right-sided heart catheterization and a mean pulmonary artery pressure of $\geq 25 \mathrm{~mm} \mathrm{Hg}$ in conjunction with a pulmonary capillary wedge pressure of $\leq 15 \mathrm{~mm} \mathrm{Hg}$. Erythrocyte sedimentation rate (ESR) and C-reactive protein (CRP) were considered elevated when each value was higher than $15 \mathrm{~mm} / \mathrm{h}$ and $0.3 \mathrm{mg} / \mathrm{dl}$, respectively.

Patients with SSc who were smokers or had respiratory disorders that might have affected DLco or VC were excluded from this study. The modified Rodnan skin score was calculated as the sum of skin thickness measurements determined by palpation on a scale of 0 to 3 in 17 body areas [20]. The study protocol was approved by The Jikei University School of Medicine, Tokyo, Japan, and informed consent was obtained from all subjects.

2.3. Enzyme-Linked Immunosorbent Assay. Fresh venous blood samples were drawn into pyrogen-free blood collection tubes without additives, immediately immersed in melting ice, and allowed to clot for $1 \mathrm{~h}$ before centrifugation. All serum samples were stored at $-70^{\circ} \mathrm{C}$ until use. The serum levels of galectin-9 and SCD155 were measured with a specific enzyme-linked immunosorbent assay kit from R\&D Systems (Minneapolis, MN) and LifeSpan BioSciences (Seattle, WA), respectively, according to the manufacturers' protocols. Each sample was tested in duplicate. The detection limits of each assay were as follows: $3 \mathrm{pg} /$ $\mathrm{ml}$ for galectin- 9 and $2.20 \mathrm{pg} / \mathrm{ml}$ for sCD155.

2.4. Statistical Analysis. Data are presented as the mean \pm standard deviation (SD). The Kruskal-Wallis test was used to compare the serum levels of galectin-9 and sCD155 between the groups, Fisher's exact probability test was used to compare frequencies, and Bonferroni's test was used for multiple comparisons. Spearman's rank correlation coefficient was used to examine the relationship between two continuous variables. Multiple linear regression analysis was used to assess the association between serum galectin-9 levels adjusted for age at onset. A probability $(P)$ value $<0.05$ was considered significant.

\section{Results}

3.1. Serum Levels of Galectin-9 and sCD155 in Patients with SSc. The serum levels of galectin-9 and sCD155 in patients with SSc and healthy controls are shown in Figure 1. The mean serum galectin-9 levels at first visit were significantly higher in patients with SSc than in healthy individuals $(20.4 \pm 8.7$ vs. $10.0 \pm 1.8 \mathrm{pg} / \mathrm{ml}$, respectively; $P<0.001)$. Among the SSc subgroups, galectin-9 levels were significantly increased in patients with dcSSc $(21.0 \pm 8.9 \mathrm{pg} / \mathrm{ml})$ and those with $\mathrm{lcSSc}(19.8 \pm 8.6 \mathrm{pg} / \mathrm{ml})$ compared with healthy individuals $(P<0.001$ for both). There was no significant difference in serum galectin-9 levels between patients with dcSSc and patients with lcSSc.

The mean serum levels of sCD155 at first visit were comparable between patients with SSc $(5618 \pm 4662 \mathrm{pg} / \mathrm{ml})$ and healthy individuals $(8592 \pm 7835 \mathrm{pg} / \mathrm{ml}$, respectively). With respect to the SSc subgroups, there was no significant difference in the serum levels of sCD155 between patients with dcSSc and patients with lcSSc. Thus, the serum levels of galectin-9, but not sCD155, were increased in patients with SSc.

3.2. Correlation between Clinical Features and Serum Galectin-9 Levels in Patients with SSc (Tables 1 and 2). Clinical and laboratory parameters obtained at the first evaluation were compared between patients with SSc and increased galectin-9 levels and patients with SSc and normal galectin-9 levels. Values greater than the mean +2 SDs $(13.5 \mathrm{pg} / \mathrm{ml})$ of control serum samples were considered to 


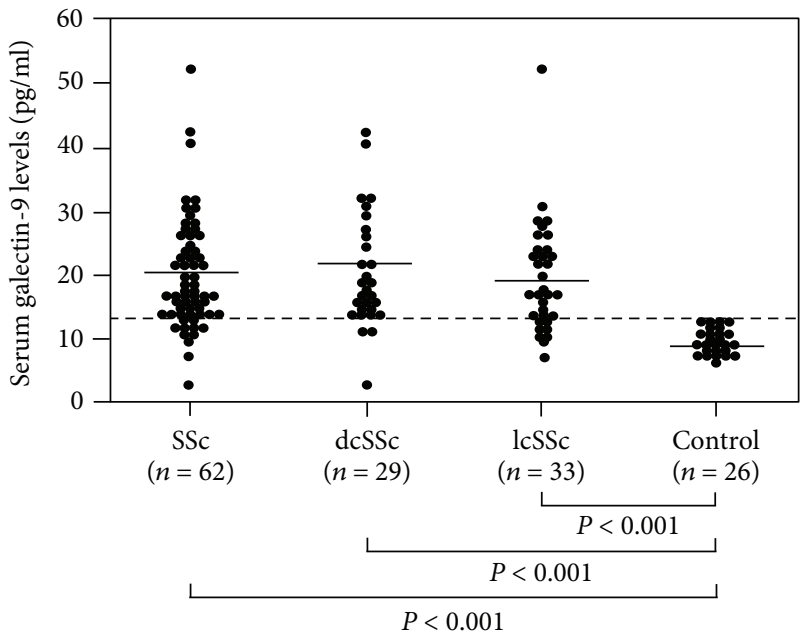

(a)

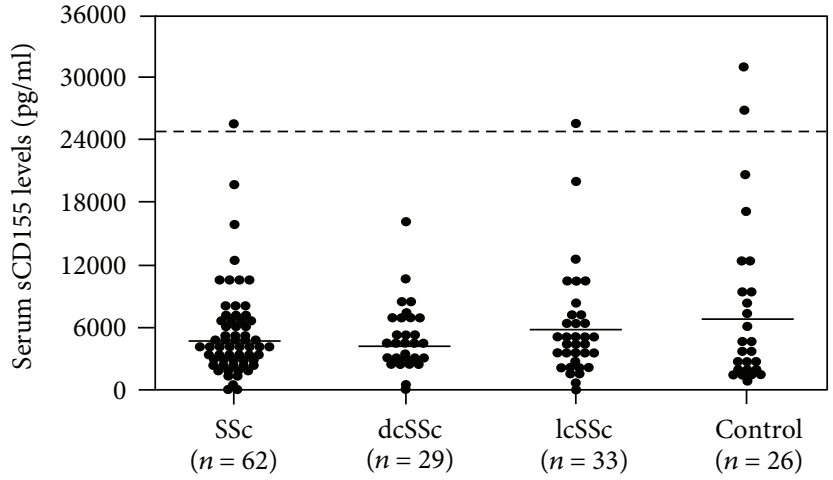

(b)

FIGURE 1: Comparison of groups according to (a) serum galectin-9 and (b) sCD155 levels. The control group comprised healthy individuals. The bars indicate the mean values in each group. The dashed line indicates the cut-off value (mean +2 SDs of control values). SSc: systemic sclerosis; dcSSc: diffuse cutaneous SSc; lcSSc: limited cutaneous SSc.

TABLE 1: Results of multiple linear regression analysis for ESR.

\begin{tabular}{lccc}
\hline $\begin{array}{l}\text { Predictive } \\
\text { variable }\end{array}$ & $\begin{array}{c}\text { Standard regression } \\
\text { coefficient }\end{array}$ & $\begin{array}{c}t \\
\text { value }\end{array}$ & $\begin{array}{c}P \\
\text { value }\end{array}$ \\
\hline Galectin-9 levels & 0.428 & 3.390 & 0.001 \\
Age at onset & 0.208 & 1.652 & 0.105 \\
\hline
\end{tabular}

ESR: erythrocyte sedimentation rate.

be increased in this study. Increased galectin-9 levels were observed in $82 \%(51 / 62)$ of all patients with SSc, $53 \%$ $(27 / 51)$ of patients with dcSSc, and $47 \%(24 / 51)$ of patients with lcSSc. Furthermore, patients with SSc and increased galectin-9 levels had an elevated ESR more frequently than those with normal galectin-9 levels $(41 \%$ vs. $0 \%$, respectively; $P=0.01$ ). Consistently, galectin-9 levels correlated positively with the ESR $(P<0.01, r=0.45$; Figure 2). Furthermore, this finding remained significant in multivariable analysis after adjustment for age at onset, suggesting that increased serum galectin-9 levels may have a greater impact on elevated ESR rather than age at onset.

The patients with SSc who died within 10 years after disease onset had higher serum galectin-9 levels $(n=4,26.8$ $\pm 7.0 \mathrm{pg} / \mathrm{ml}$ ) than those who survived at least 10 years $(n=58,20.0 \pm 8.8 \mathrm{pg} / \mathrm{ml})$, although the difference was not statistically significant $(P=0.05)$. Furthermore, all 4 SSc patients who died within 10 years after disease onset had increased serum galectin-9 levels $(33.1,31.1,24.0$, and $19.0 \mathrm{pg} / \mathrm{ml}$ ). Therefore, increased serum galectin-9 levels may predict mortality in patients with SSc.

\section{Discussion}

In this study, patients with SSc exhibited raised serum galectin-9 levels, but not sCD155 levels. Serum galectin-9 levels were raised not only in patients with dcSSc but also in patients with lcSSc. Elevated galectin-9 levels correlated positively with the ESR. Furthermore, increased serum galectin- 9 levels tended to be associated with higher mortality and serious organ involvement. These results suggest that galectin-9 may play an important role in the pathogenesis of SSc.

Galectin-9 is a ligand of TIM-3, is expressed highly on $\mathrm{CD}^{+}{ }^{+} \mathrm{T}$ helper (Th) 1 and Th17 cells, but not on Th2 cells, and provides inhibitory signals through its interaction with TIM-3 [7]. Galectin-9 is upregulated in dermal fibroblast in patients with SSc [21]. In a bleomycin-induced mouse model of SSc, galectin-9 suppression using Lgals9 small interfering RNA attenuates skin fibrosis, while it augments the expression of interferon- $\gamma$, leading to Th1-skewed immune polarization [21]. Considering that SSc is regarded as a Th2/Th17-polarized autoimmune disease [22, 23], increased circulating levels of galectin- 9 may cause a Th2-predominant immune imbalance, thereby inducing the pathological progression of SSc.

Several reports have revealed that an elevated ESR is associated with a higher mortality rate in patients with SSc [24-27]. An elevated ESR has also been reported to be a predictor of pulmonary arterial hypertension [28]. Consistent with this, SSc patients with elevated serum galectin-9 levels tended to have the diffuse cutaneous subtype and vital organ involvement more frequently than those with normal serum galectin-9 levels, although the differences were not statistically significant. Thus, elevated serum galectin-9 levels may also be a predictor of serious organ involvement and high mortality in patients with SSc, similar to an elevated ESR.

There are several potential limitations of this study that should be considered. First, the patient population was relatively small; a larger study is essential to confirm 
TABLE 2: Clinical and laboratory findings in patients with SSc according to serum galectin-9 levels.

\begin{tabular}{|c|c|c|c|}
\hline & $\begin{array}{c}\text { Elevated } \\
\text { galectin-9 } \\
n=51\end{array}$ & $\begin{array}{c}\text { Normal } \\
\text { galectin-9 } \\
n=11\end{array}$ & $\begin{array}{c}P \\
\text { value }\end{array}$ \\
\hline $\begin{array}{l}\text { Age at onset, years } \\
(\text { mean } \pm S D)\end{array}$ & $53 \pm 15$ & $46 \pm 11$ & 0.07 \\
\hline Male : female & $2: 49$ & $0: 11$ & $>0.99$ \\
\hline $\begin{array}{l}\text { MRSS, points } \\
(\text { mean } \pm S D)\end{array}$ & $10.2 \pm 8.7$ & $6.1 \pm 5.6$ & 0.27 \\
\hline \multicolumn{4}{|l|}{ Clinical features (\%) } \\
\hline dcSSc & 53 & 27 & 0.19 \\
\hline lcSSc & 47 & 73 & 0.19 \\
\hline $\begin{array}{l}\text { Pitting scars/digital } \\
\text { ulcers }\end{array}$ & 37 & 27 & 0.73 \\
\hline $\begin{array}{l}\text { Contracture of } \\
\text { phalanges }\end{array}$ & 47 & 36 & 0.74 \\
\hline Diffuse pigmentation & 37 & 9 & 0.09 \\
\hline Telangiectasia & 24 & 27 & $>0.99$ \\
\hline \multicolumn{4}{|l|}{ Organ involvement (\%) } \\
\hline $\begin{array}{l}\text { Interstitial lung } \\
\text { disease }\end{array}$ & 47 & 27 & 0.32 \\
\hline Decreased \%VC & 22 & 0 & 0.19 \\
\hline Decreased \%DLco & 47 & 27 & 0.32 \\
\hline $\begin{array}{l}\text { Pulmonary } \\
\text { hypertension }\end{array}$ & 4 & 0 & $>0.99$ \\
\hline Esophagus & 63 & 91 & 0.43 \\
\hline Heart & 10 & 0 & 0.58 \\
\hline Kidney & 4 & 0 & $>0.99$ \\
\hline Joint & 25 & 18 & $>0.99$ \\
\hline Muscle & 20 & 9 & 0.67 \\
\hline \multicolumn{4}{|l|}{ Laboratory findings (\%) } \\
\hline $\begin{array}{l}\text { Antitopoisomerase I } \\
\text { Abs }\end{array}$ & 39 & 27 & 0.52 \\
\hline Anticentromere Abs & 43 & 55 & 0.52 \\
\hline Elevated ESR & $41^{*}$ & 0 & 0.01 \\
\hline Elevated CRP & 12 & 0 & 0.58 \\
\hline
\end{tabular}

Values were taken on the first visit. ${ }^{*} P<0.05$ versus SSc patients with normal serum galectin-9 levels. SSc: systemic sclerosis; SD: standard deviation; MRSS: modified Rodnan skin score; dcSSc: diffuse cutaneous systemic sclerosis; lcSSc: limited cutaneous SSc; VC: vital capacity; DLco: diffusion capacity for carbon monoxide; Abs: antibodies; ESR: erythrocyte sedimentation rate; CRP: C-reactive protein.

our results. Second, all patients with SSc and healthy individuals in this study were Japanese; additional studies are needed to verify these findings in other ethnic groups. Third, the precise mechanism by which galectin- 9 contributes to the pathogenesis of SSc was not clarified. Fourth, it will be important to examine the longitudinal changes of serum galectin-9 levels in patients with SSc and to assess their association with ESR, mortality, serious organ involvement, in particular, interstitial lung disease and pulmonary arterial hypertension, and disease activity in the future studies. Nevertheless, our findings suggest that

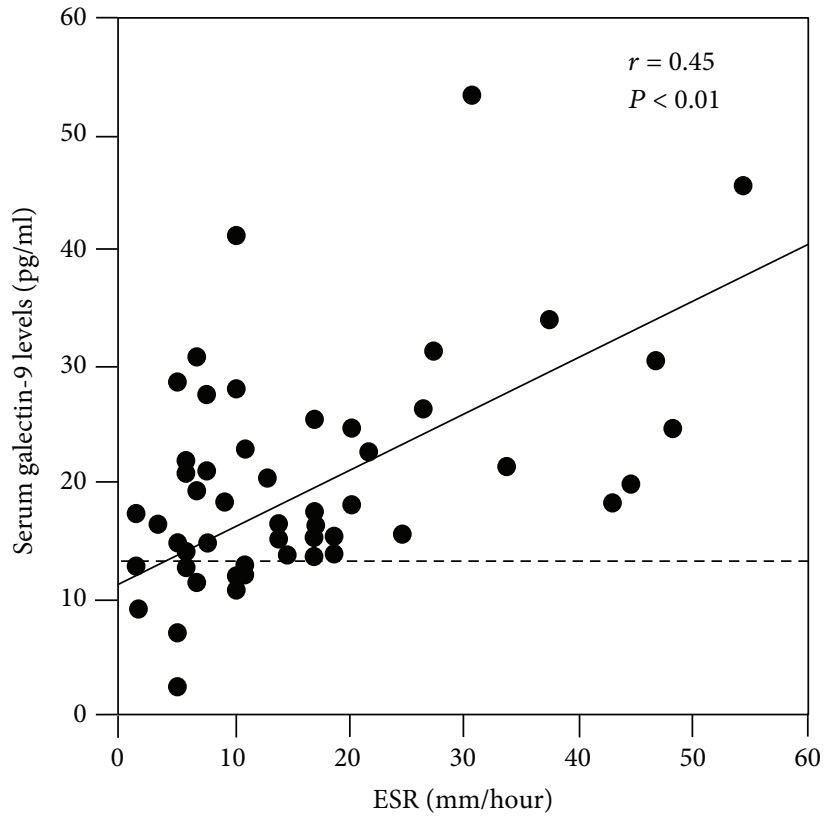

FIgURE 2: Correlation between serum galectin-9 levels and the ESR in patients with SSc. The dashed line indicates the cut-off value. ESR: erythrocyte sedimentation rate.

galectin-9 may be involved in the pathogenesis of SSc. Moreover, we did not find a significant increase in serum sCD155 levels in patients with SSc in the current study; however, this does not necessarily exclude a role for these coinhibitory receptors in the pathogenesis of SSc.

\section{Data Availability}

The data used to support the findings of this study are available from the corresponding author upon request.

\section{Conflicts of Interest}

The authors have no conflicts of interest.

\section{References}

[1] K. Yanaba, "Strategy for treatment of fibrosis in systemic sclerosis: present and future," The Journal of Dermatology, vol. 43, no. 1, pp. 46-55, 2016.

[2] R. Fleischmajer, J. S. Perlish, and J. R. T. Reeves, "Cellular infiltrates in scleroderma skin," Arthritis \& Rheumatism, vol. 20, no. 4, pp. 975-984, 1977.

[3] A. D. Roumm, T. L. Whiteside, T. A. Medsger, and G. P. Rodnan, "Lymphocytes in the skin of patients with progressive systemic sclerosis. Quantification, subtyping, and clinical correlations," Arthritis \& Rheumatism, vol. 27, no. 6, pp. 645-653, 1984.

[4] K. Yanaba, Y. Asano, S. Noda et al., "Increased circulating fibrinogen-like protein 2 in patients with systemic sclerosis," Clinical Rheumatology, vol. 32, no. 1, pp. 43-47, 2013.

[5] F. A. Schildberg, S. R. Klein, G. J. Freeman, and A. H. Sharpe, "Coinhibitory pathways in the B7-CD28 ligand-receptor family,” Immunity, vol. 44, no. 5, pp. 955-972, 2016. 
[6] K. J. Lafferty and A. J. Cunningham, "A new analysis of allogeneic interactions," The Australian Journal of Experimental Biology and Medical Science, vol. 53, no. 1, pp. 27-42, 1975.

[7] A. C. Anderson, N. Joller, and V. K. Kuchroo, "Lag-3, Tim-3, and TIGIT: co-inhibitory receptors with specialized functions in immune regulation," Immunity, vol. 44, no. 5, pp. 9891004, 2016.

[8] A. B. Adams, M. L. Ford, and C. P. Larsen, "Costimulation blockade in autoimmunity and transplantation: the CD28 pathway," Journal of Immunology, vol. 197, no. 6, pp. 20452050, 2016.

[9] M. Ponsoye, C. Frantz, N. Ruzehaji et al., "Treatment with abatacept prevents experimental dermal fibrosis and induces regression of established inflammation-driven fibrosis," Annals of the Rheumatic Diseases, vol. 75, no. 12, pp. 2142-2149, 2016.

[10] E. F. Chakravarty, V. Martyanov, D. Fiorentino et al., "Gene expression changes reflect clinical response in a placebocontrolled randomized trial of abatacept in patients with diffuse cutaneous systemic sclerosis," Arthritis Research \& Therapy, vol. 17, no. 1, p. 159, 2015.

[11] S. Sato, M. Fujimoto, M. Hasegawa et al., "Serum soluble CTLA-4 levels are increased in diffuse cutaneous systemic sclerosis," Rheumatology (Oxford), vol. 43, no. 10, pp. 1261-1266, 2004.

[12] M. Chiba, K. Yanaba, M. Hayashi, Y. Yoshihara, and H. Nakagawa, "Clinical significance of serum soluble T-cell immunoglobulin and mucin domain 3 levels in systemic sclerosis: association with disease severity," The Journal of Dermatology, vol. 44, no. 2, pp. 194-197, 2017.

[13] K. Yanaba, M. Hayashi, Y. Yoshihara, and H. Nakagawa, "Serum levels of soluble programmed death-1 and programmed death ligand-1 in systemic sclerosis: association with extent of skin sclerosis," The Journal of Dermatology, vol. 43, no. 8, pp. 954-957, 2016.

[14] F. van den Hoogen, D. Khanna, J. Fransen et al., "2013 classification criteria for systemic sclerosis: an American College of Rheumatology/European League against Rheumatism collaborative initiative," Arthritis \& Rheumatism, vol. 65, no. 11, pp. 2737-2747, 2013.

[15] A. T. Masi and Subcommittee For Scleroderma Criteria of the American Rheumatism Association Diagnostic and Therapeutic Criteria Committee, "Preliminary criteria for the classification of systemic sclerosis (scleroderma). Subcommittee for scleroderma criteria of the American rheumatism association diagnostic and therapeutic criteria committee," Arthritis \& Rheumatism, vol. 23, no. 5, pp. 581-590, 1980.

[16] E. C. LeRoy, C. Black, R. Fleischmajer et al., "Scleroderma (systemic sclerosis): classification, subsets and pathogenesis," The Journal of Rheumatology, vol. 15, no. 2, pp. 202-205, 1988.

[17] S. Sato, H. Ihn, K. Kikuchi, and K. Takehara, "Antihistone antibodies in systemic sclerosis: association with pulmonary fibrosis," Arthritis \& Rheumatism, vol. 37, no. 3, pp. 391394, 1994.

[18] V. D. Steen, D. L. Powell, and T. A. Medsger, "Clinical correlations and prognosis based on serum autoantibodies in patients with systemic sclerosis," Arthritis \& Rheumatism, vol. 31, no. 2, pp. 196-203, 1988.

[19] K. Yanaba, Y. Asano, K. Akamata et al., "Circulating galectin-1 concentrations in systemic sclerosis: potential contribution to digital vasculopathy," International Journal of Rheumatic Diseases, vol. 19, no. 6, pp. 622-627, 2016.
[20] P. J. Clements, P. A. Lachenbruch, J. R. Seibold et al., "Skin thickness score in systemic sclerosis: an assessment of interobserver variability in 3 independent studies," The Journal of Rheumatology, vol. 20, no. 11, pp. 1892-1896, 1993.

[21] R. Saigusa, Y. Asano, K. Nakamura et al., "Systemic sclerosis dermal fibroblasts suppress Th1 cytokine production via galectin- 9 overproduction due to Fli1 deficiency," The Journal of Investigative Dermatology, vol. 137, no. 9, pp. 1850-1859, 2017.

[22] T. Matsushita, M. Hasegawa, Y. Hamaguchi, K. Takehara, and S. Sato, "Longitudinal analysis of serum cytokine concentrations in systemic sclerosis: association of interleukin 12 elevation with spontaneous regression of skin sclerosis," The Journal of Rheumatology, vol. 33, no. 2, pp. 275-284, 2006.

[23] C. Chizzolini, A. M. Dufour, and N. C. Brembilla, "Is there a role for IL-17 in the pathogenesis of systemic sclerosis?," Immunology Letters, vol. 195, pp. 61-67, 2018.

[24] L. Scussel-Lonzetti, F. Joyal, J. P. Raynauld et al., "Predicting mortality in systemic sclerosis: analysis of a cohort of 309 French Canadian patients with emphasis on features at diagnosis as predictive factors for survival," Medicine, vol. 81, no. 2, pp. 154-167, 2002.

[25] C. Bryan, Y. Howard, P. Brennan, C. Black, and A. Silman, "Survival following the onset of scleroderma: results from a retrospective inception cohort study of the UK patient population," British Journal of Rheumatology, vol. 35, no. 11, pp. 1122-1126, 1996.

[26] C. Bryan, C. Knight, C. M. Black, and A. J. Silman, "Prediction of five-year survival following presentation with scleroderma: development of a simple model using three disease factors at first visit," Arthritis \& Rheumatism, vol. 42, no. 12, pp. 2660 2665, 1999.

[27] C. Ferri, G. Valentini, F. Cozzi et al., "Systemic sclerosis: demographic, clinical, and serologic features and survival in 1,012 Italian patients," Medicine, vol. 81, no. 2, pp. 139-153, 2002.

[28] Y. Allanore, D. Borderie, J. Avouac et al., "High N-terminal pro-brain natriuretic peptide levels and low diffusing capacity for carbon monoxide as independent predictors of the occurrence of precapillary pulmonary arterial hypertension in patients with systemic sclerosis," Arthritis \& Rheumatism, vol. 58, no. 1, pp. 284-291, 2008. 


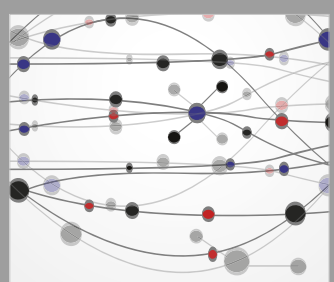

The Scientific World Journal
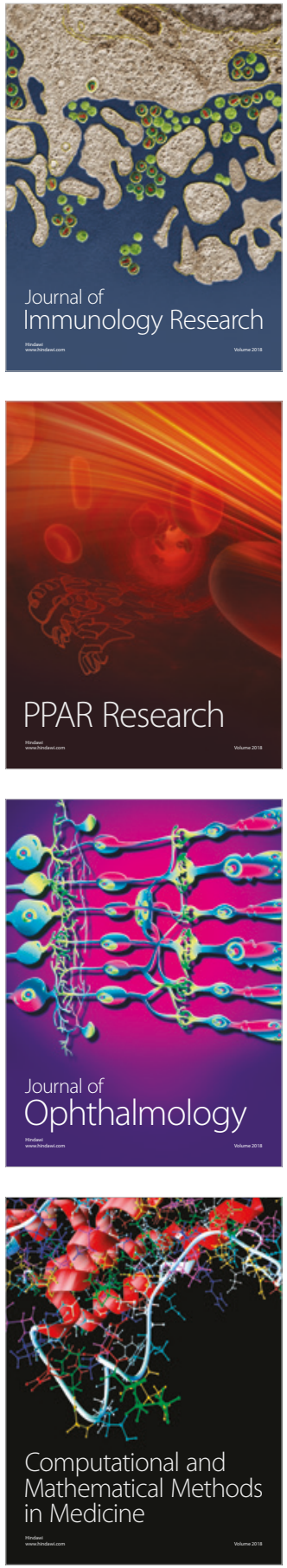

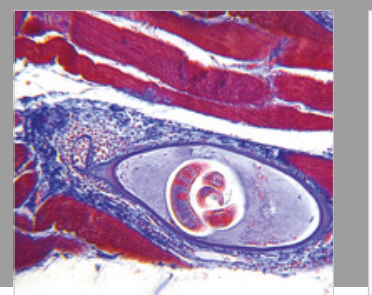

Gastroenterology Research and Practice

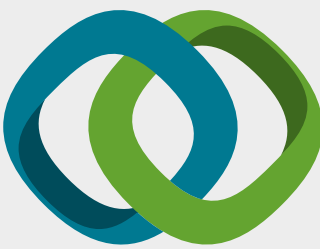

\section{Hindawi}

Submit your manuscripts at

www.hindawi.com
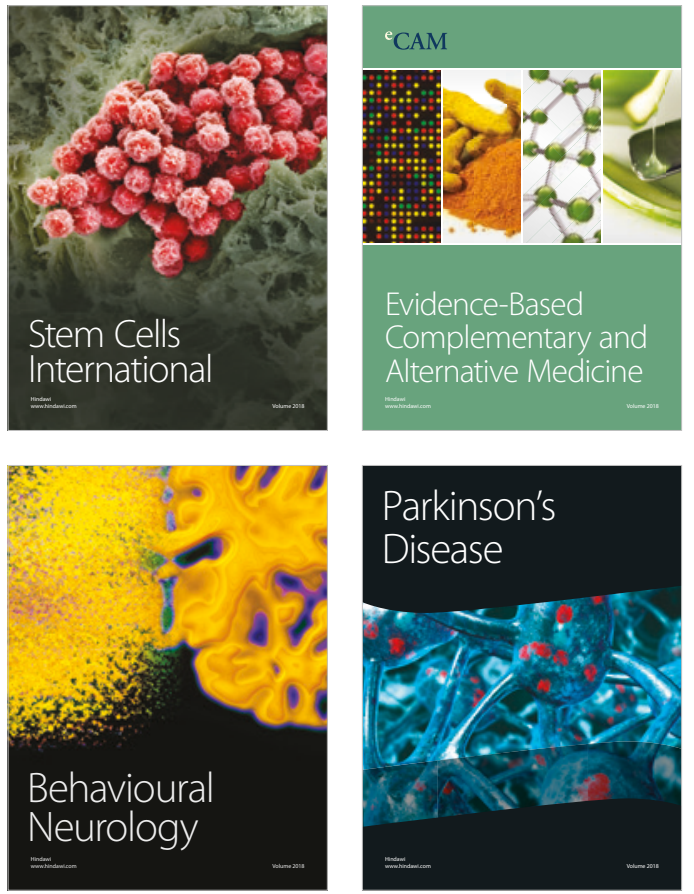

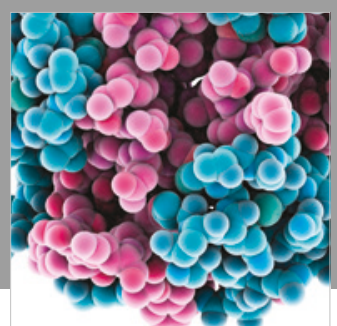

ournal of

Diabetes Research

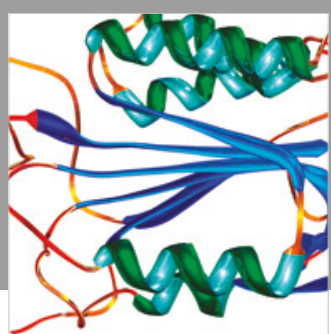

Disease Markers
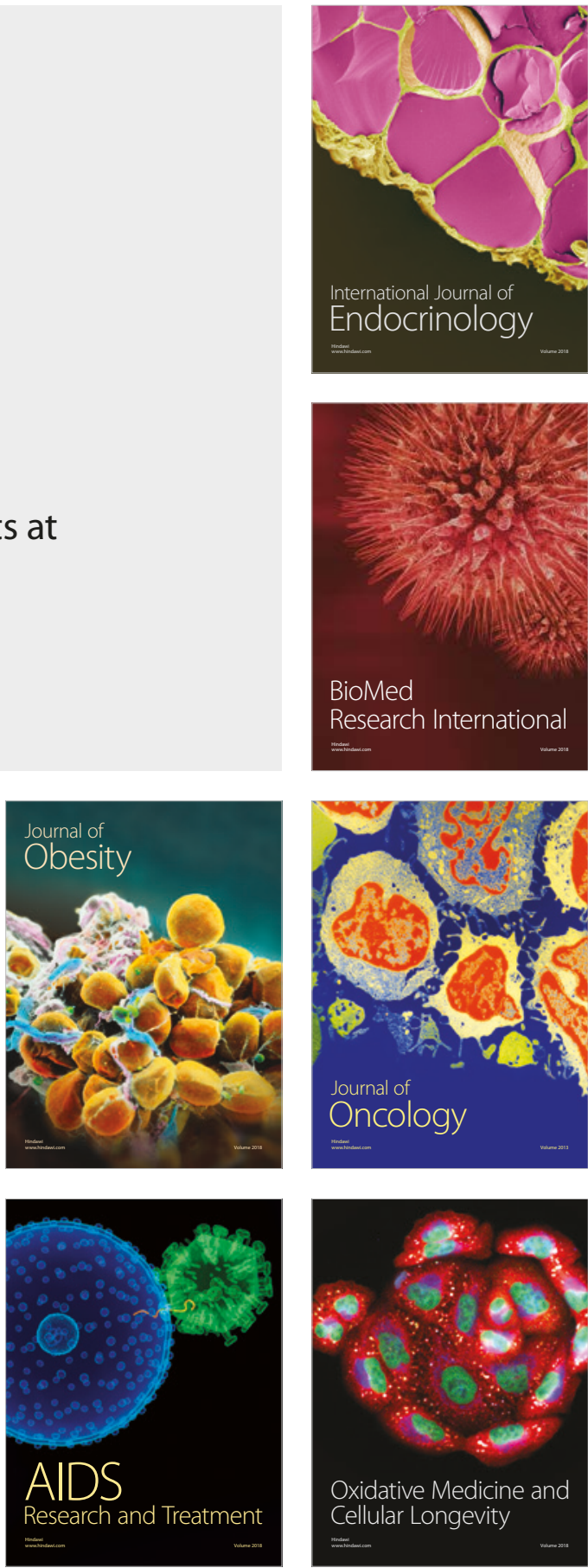